\title{
DESAFIOS ENFRENTADOS PELOS AGENTES COMUNITÁRIOS DE SAÚDE NA ESTRATÉGIA SAÚDE DA FAMÍLIA
}

\section{Challenges Facing the Community Health Agents in Family Health Strategy*}

Michele Goulart dos Santos, Luciane Bisognin Ceretta, Magada Tessmann Schwalm, Valdemira Santina Dagostim, Maria Tereza Soratto

Curso de Enfermagem - Universidade do Extremo Sul Catarinense - UNESC -

Criciúma - SC - Brasil

Endereço para correspondência:

Maria Tereza Soratto

Curso de Enfermagem

Universidade do Extremo Sul Catarinense - UNESC

Avenida Universitária, 1105

Criciúma - SC

CEP - 88806-000

Email: guiga@unesc.net 


\title{
Resumo
}

A pesquisa teve como objetivo conhecer os desafios enfrentados pelos Agentes Comunitários de Saúde (ACS) no processo de trabalho na Unidade de Estratégia Saúde da Família (ESF) de um município da Região Sul de Santa Catarina. Trata-se de uma pesquisa de abordagem qualitativa, do tipo descritivo-exploratória e de campo. Utilizou-se como instrumento de coleta de dados a entrevista semiestruturada aplicada com sete ACS que atuam nas ESF. Utilizou-se para análise dos dados as categorias de análise preconizadas por Minayo. Os ACS ressaltaram as dificuldades enfrentadas para encontrar as pessoas em casa, o mau tempo, a distância entre uma casa e outra, os animais soltos, a precarização das estradas e as casas fechadas; além da vulnerabilidade social da microárea com casos de tráfico de drogas, a falta de infra-estrutura na comunidade e a ocorrência de doenças infecto-contagiosas. O ouvir atento com esclarecimento das dúvidas, dar atenção ao problema das famílias de forma discreta e com ética profissional são condutas dos ACS para o enfrentamento das dificuldades e desafios no processo de trabalho na ESF. O papel do enfermeiro no processo de trabalho do agente comunitário perpassa o esclarecimento de dúvidas e a resolução dos problemas encontrados em cada microárea.

Palavras-chave: Estratégia Saúde da Família (ESF); Agentes Comunitários de Saúde; Ambiente de Trabalho.

\begin{abstract}
The research aimed to meet the challenges faced by community health Agents in the process of work on the family health Strategy Unit of a town in the southern region of Santa Catarina. It is a qualitative research, descriptive and exploratory type of field. Used as the data collection instrument a semi-structured interview applied with seven community health Agents working in the family health strategy. It was used for analysis of data the categories of analysis proposed by Minayo. The communitarian agents of Health stressed the difficulties faced to find people at home, bad weather, the distance between a House and other loose animals, the precariousness of the roads and the houses closed; Besides the social vulnerability of micro-sectors with cases of drug trafficking, the lack of infrastructure in the community and occurrence
\end{abstract}


Artigo Original

Atenção à Saúde

of infectious diseases. The hearing focused on clarification of doubts, give attention to the problem of the families discreetly and with professional ethics are conduits of communitarian agents of Health to deal with the difficulties and challenges in the process of work on the family health strategy. The nurse's role in the process of community Agent job runs through the clarification of doubts and the resolution of the problems encountered in each micro-sectors.

Keywords: The family health strategy; Community health workers; Desktop.

\section{INTRODUÇÃO}

O Sistema Único de Saúde (SUS) é um dos maiores sistemas públicos de saúde do mundo. Ele compreende desde um simples atendimento ambulatorial até procedimentos mais complexos. Criado em 1988 pela Constituição Federal Brasileira para ser o sistema de saúde dos mais de 180 milhões de brasileiros. Oferece consultas, exames e internações, também promove campanhas e ações de prevenção e de vigilância sanitária, contribuindo desta forma para uma maior qualidade de vida para toda população brasileira ${ }^{1}$.

O Sistema Único de Saúde objetiva promover o direito social, atribuindo assim a participação e os direitos de igualdade na saúde pública, focando-se na atenção primária aos indivíduos de forma coletiva ou não, para que sejam avaliadas as reais dificuldades encontradas ${ }^{2}$.

Entende-se assim que para que o serviço do SUS funcione de maneira positiva, a rotina de trabalho de uma Unidade de ESF precisa tornar-se bastante abrangente, contando com uma gama grande de profissionais distintos para atender as prioridades e realizar acolhimento qualificado para diferentes comunidades. $O$ trabalho dos Agentes Comunitários de Saúde (ACS) dentro de uma ESF implica em um constante aperfeiçoamento pedagógico diante de educação permanente em saúde, sendo esta juntamente apoiada pelo enfrentamento psicológico e mental para os mesmos, que se expõem a múltiplas realidades diferenciadas a cada dia de trabalho encarado dentro de cada microrregião/área. Toda população que deste estabelecimento depende, sabe e acredita fervorosamente que estes profissionais 
são sim o verdadeiro "elo" entre a própria comunidade e a Unidade de Saúde, criando assim um vínculo afetivo ainda maior do que se espera normalmente.

Diante do descrito acima, uma capacitação para agentes acontecida no ano de 2010 ressalta que o Agente Comunitário de Saúde trabalha juntamente com toda equipe da ESF, composta por: enfermeiros, técnicos e auxiliares de enfermagem, odontólogos, médicos, recepcionistas, entre outros. Atuam, deste modo, como coadjuvantes no processo de saúde-doença, realizando atividades de prevenção de doenças e promoção da saúde, fazendo também a busca de pacientes em estados críticos $^{3}$.

A criação da profissão de agente comunitário de saúde ocorreu recentemente, por meio da lei n.- $10.507 / 02$. Em 2006, foi promulgada a Emenda Constitucional n. 51 (EC 51), que prevê a possibilidade de contratação desse trabalhador através de processo seletivo público. Posteriormente, a EC 51 foi regulamentada pela lei n. $-11.350 / 06$, mas ainda não há garantia efetiva da formalização da contratação nem clareza quanto ao processo de trabalho. Residir na comunidade onde irá atuar, ter concluído o ensino fundamental e haver concluído com aproveitamento o curso de qualificação básica para a formação de agente comunitário de saúde são alguns dos requisitos estabelecidos para ser contratado como ACS. Anteriormente à nova lei, era necessário apenas que o ACS soubesse ler e escrever ${ }^{4}$.

O ACS resultou da criação do Programa dos Agentes Comunitários de Saúde (do PACS) em 1991, como parte do processo de construção do Sistema Único de Saúde, estabelecido por norma constitucional em $1988^{5}$.

O propósito primordial destes agentes é de participar da vida da comunidade, principalmente através das organizações, estimulando a discussão das questões relativas à melhoria de vida, focada em uma qualidade satisfatória; informando, assim, aos demais membros da equipe de saúde da disponibilidade, necessidades e dinâmica social da tal comunidade em que estão inseridos².

Com isto identifica-se que este trabalhador enfrenta constantemente grandes desafios e dificuldades que necessitam ser encarados para que o trabalho continue, e para que a comunidade em si receba ainda uma cobertura na sua área diante da saúde. Este trabalho visa, então, entender como se dá o processo de trabalho dos Agentes Comunitários de Saúde - ACS, bem como se desenvolve a capacitação 
para tal cargo, junto àsfacilidades e dificuldades estabelecidas, as quais sabemos que são muitas a cada dia.

No campo das políticas públicas, o setor da saúde se destaca na maioria das vezes por defender uma proposta positiva de mudança, implicando assim nas reformas administrativas, políticas e organizativas a partir do novo desenho de modelo público de oferta de serviços e ações. Mesmo assim essas práticas não foram suficientes para mudar a realidade nacional e suas reais condições de vida e saúde da população brasileira ${ }^{6}$.

A Estratégia de Saúde da Família - ESF é entendida como uma administração pautada no modelo assistencial, adaptada com implantação de equipes multiprofissionais em unidades básicas de saúde. Estes profissionais, como toda a equipe, são responsáveis pelo acompanhamento de um número apurado de famílias, estas, localizadas em uma área geográfica demarcada. Os profissionais envolvidos nesta estratégia preocupam-se atuando com ações de promoção da saúde, prevenção, recuperação, reabilitação de doenças e agravos mais frequentes, e na manutenção da saúde desta comunidade ${ }^{7}$.

O Ministério da Saúde adotou como medida colocar em seu plano de Ações e Metas Prioritárias as Estratégias de Saúde da Família e Agentes Comunitários de Saúde como caminhos plausíveis na arte da reorganização da atenção básica em saúde ( $\mathrm{AB}$ ), com a certeza de que as mesmas já são formadas por uma realidade concreta no contexto da mudança do modelo assistencial no qual o Brasil já se empenha. Ele também ressalta que o trabalho do ACS deve permanecer constante, sendo permanente, sendo que o Brasil hoje em dia possui mais de 200 mil ACS atuando 8 .

Percebe-se que o ACS possui um papel importante, uma vez que também atua no mecanismo do Sistema Único de Saúde, fortalecendo a integração entre a comunidade e a Atenção Primária.

A ESF busca reorganizar os serviços e as práticas profissionais focando na promoção da saúde, prevenção de doenças e reabilitação, permitindo assim uma promoção de qualidade de vida da população, pautada nos princípios do SUS, bem como o da integralidade e multidisciplinaridade.

A estratégia deve oferecer atenção integral e contínua à saúde da comunidade, seja ela individualmente ou através de grupos, com ações de 
promoção, proteção e recuperação da saúde. Estas ações devem estar centradas na família, diante do ambiente socioeconômico e cultural ${ }^{9}$.

Ao SUS cabe a tarefa de promover e proteger a saúde, como direito de todos e dever do estado. Assim, para cumprir tal tarefa, ele precisa se organizar conforme alguns princípios previstos no artigo 198 da Constituição Federal de 1988, e na Lei 8.080/1990, sejam eles: universalidade, integralidade, equidade, participação da comunidade, descentralização, regionalização, hierarquização ${ }^{10}$.

Dessa forma, a família passou a ser o centro da atenção, entendida a partir do seu ambiente físico e social, onde às equipes de saúde contribuem com uma compreensão ampliada do processo saúde/doença e da necessidade de intervenções ${ }^{6}$.

O papel de um ACS de confiança e que mantenha sua ética e postura profissional dentro de uma ESF e fora dela, seja na comunidade ou nos lugares que a cercam,é de suma importância para que se realize um trabalho fidedigno e comprometido com o bem-estar de todos. Para que isto ocorra é necessária uma equipe comunicativa e participativa, procurando atender toda a demanda através de visitas domiciliares, palestras nos grupos, consultas, dispensação de medicamentos, triagens, curativos, injetáveis, procedimentos de observação e orientações.

O agente de saúde é um trabalhador que surgiu de uma experiência no estado do Ceará em 1987, e atualmente está inserido da saúde da família, sendo que desde julho de 2002 foi reconhecido como uma categoria profissional caracterizada pelo exercício de atividades voltadas para prevenção e promoção dentro da saúde pública ${ }^{11}$.

A busca pela saúde está associada a vários recursos: médicos, odontológicos, psicológicos, enfermeiros, nutricionais, podendo contribuir através destes para a melhoria do atendimento à comunidade, uma vez que a população desperta um interesse cada vez maior para uma vida mais saudável. Essa busca relaciona-se com o uso correto de medicamentos, controle da pressão arterial, conversa com pessoas bem instruídas da área da saúde que passem informações coerentes de acordo com a necessidade de cada cidadão. Desde o estabelecimento do Sistema Único de Saúde (SUS) tem-se buscado reorientar o modelo de atenção, enfatizando-se a atenção básica e a saúde familiar e não mais o modelo hospitalocêntrico curativista². 
Neste contexto, o enfermeiro deve estar preparado tecnicamente e psicologicamente para fornecer não somente ao paciente, mas também a toda sua equipe, como por exemplo, os ACS (foco do estudo), todo apoio técnico e emocional, amparando-o em todos os aspectos do processo de trabalho, diante das dificuldades e enfrentamentos, bem como ser um líder sempre disposto a mudanças positivas e a novas idéias. Sob este ponto de vista o profissional enfermeiro atua não somente como "líder", mas como um amigo, que abre espaço para conversas e troca de saberes e experiências, as quais valem muito para o aprendizado de todos.

Contudo, este trabalho se torna importante para saber como anda o processo de aperfeiçoamento, educação permanente, bem como dificuldades, enfrentamentos e até mesmo facilidades encontradas por estes profissionais que entram na casa da família e acabam na maioria das vezes se tornando um membro desta. É importante destacarmos que como qualquer outro profissional, estes precisam dispor de tempo, calma e atuar também como aconselhadores em várias situações.

A partir destas reflexões tem-se como problema de pesquisa: Quais os desafios enfrentados pelos ACS no processo de trabalho na Unidade de ESF?

Considera-se como pressupostos que os maiores desafios enfrentados pelo ACS no processo de trabalho na ESF está relacionado à: acolhimento e vínculo com algumas famílias; falta de entendimento das famílias sobre o papel dos ACS na ESF; limites éticos no exercício profissional; falta de resolutividade dos casos; remuneração; falta de capacitação contínua ou programa de educação permanente, a partir da realidade vivenciada.

Nesta perspectiva, este estudo teve por objetivo conhecer os desafios enfrentados pelos ACS no processo de trabalho na Unidade de ESF.

\section{METODOLOGIA}

Trata-se de uma pesquisa de abordagem qualitativa, descritivo-exploratória e de campo. Foi realizada em uma Estratégia de Saúde da Família, de um município do Sul de Santa Catarina. Os sujeitos do estudo constituíram-se de sete Agentes Comunitários de Saúde - ACS, que atuam na Unidade de Saúde da Família. A 
Artigo Original

Atenção à Saúde

pesquisa teve como instrumento para coleta de dados a entrevista semi-estruturada. As informações foram analisadas pela categorização de dados ${ }^{12}$.

A pesquisa seguiu o disposto na Resolução n. 466/12 do Conselho Nacional de Saúde ${ }^{13}$ e foi aprovada pelo Comitê de Ética da UNESC - CEP n. 134342/2012.

Para preservar o sigilo decorrente das entrevistas realizadas com a equipe de agentes, de acordo com as diretrizes e normas regulamentadoras da Resolução n. 466/12, que envolvem pesquisa com seres humanos e grupos vulneráveis ${ }^{13}$, utilizou-se a letra "ACS" para os agentes comunitários de saúde participantes da pesquisa seguidos do respectivo número.

\section{RESULTADOS E DISCUSSÃO}

\section{Perfil das ACS}

Todas as ACS são do sexo feminino, idade entre 22 e 54 anos, quatro (ACS2; ACS4; ACS5; ACS6) possuem ensino fundamental completo, duas (ACS3; ACS1) possuem ensino médio incompleto e a ACS7 ensino médio completo. Em relação ao tempo de atuação na Unidade, as ACS possuem de 1 ano e 5 meses a 8 anos de atuação, demonstrando uma grande variedade de tempo de trabalho na ESF. Todas as ACS realizaram processo seletivo para trabalhar na ESF.

A capacitação das ACS abrangeu temas referentes ao processo de trabalho do ACS e equipe de saúde, como o trabalho e o papel dos agentes comunitários, Leis do SUS, preconceito, democracia, direitos e deveres do profissional, saúde da criança abordando os cuidados com o recém-nascido $(R N)$ e amamentação, saúde da mulher, ética do trabalho, programa da dengue, saúde bucal, saúde do idoso, envelhecimento, saúde do adolescente, Doenças Sexualmente Transmissíveis (DSTs), imunização, doenças infecto-contagiosas, epidemiologia, prevenção de doenças, processo saúde-doença, políticas de saúde no Brasil, trabalho em equipe e a interdisciplinaridade, cuidados dentro do domicílio, abordagem e acolhimento da família, como destacado no Quadro 1. 
Artigo Original

Atenção à Saúde

Quadro 1. Capacitação do ACS para o processo de trabalho na Estratégia de Saúde da Família

\begin{tabular}{|c|c|}
\hline Capacitação dos ACS & ACS (Agentes Comunitários de Saúde) \\
\hline Imunização & (05) ACS3; ACS4; ACS5; ACS6; ACS7 \\
\hline O trabalho e papel do ACS & (04) ACS1; ACS3; ACS4; ACS5 \\
\hline $\begin{array}{l}\text { Lei do SUS, Preconceito, Democracia, } \\
\text { Direitos e Deveres do profissional }\end{array}$ & (04) ACS1; ACS4; ACS5; ACS6 \\
\hline $\begin{array}{l}\text { Saúde da Criança, Cuidados com o RN, } \\
\text { Amamentação }\end{array}$ & (04) ACS1; ACS2; ACS6; ACS7 \\
\hline $\begin{array}{l}\text { Doenças Sexualmente Transmissíveis } \\
\text { (DST's) }\end{array}$ & (03) ACS2; ACS3; ACS5 \\
\hline Doenças Infecto-Contagiosas & (03) ACS3; ACS4; ACS6 \\
\hline $\begin{array}{l}\text { Epidemiologia, Prevenção de doenças, } \\
\text { Processo Saúde-Doença }\end{array}$ & (03) ACS3; ACS5; ACS6 \\
\hline Trabalho em equipe, Interdisciplinaridade & (02) ACS3; ACS6 \\
\hline Saúde Bucal & (02) ACS2; ACS5 \\
\hline Saúde do Idoso, Envelhecimento & (02) ACS2; ACS5 \\
\hline Saúde da mulher & (02) ACS1; ACS5 \\
\hline Ética do trabalho & (01)ACS1 \\
\hline Programa da Dengue & (01)ACS1 \\
\hline Saúde do Adolescente & (01)ACS1 \\
\hline Políticas de Saúde no Brasil & (01)ACS3 \\
\hline Cuidados em Domicílio & (01)ACS5 \\
\hline Abordagem e acolhimento da família & (01)ACS7 \\
\hline
\end{tabular}

Fonte: Dados da pesquisa, 2013.

Quanto a carga horária destas capacitações realizadas, variou de 116 a 1000 horas, dentre os anos de 2007 a 2012.

Contudo, sua formação para o desempenho dessas funções precisa ser revista, considerando a amplitude do seu papel. A profissionalização dos ACS deve ser concebida como um processo voltado para a realidade em que está inserido. 
Artigo Original

Atenção à Saúde

Essa percepção do ambiente e da cultura local deve estar claramente presente no desempenho de suas funções. Esse olhar se fundamenta no fato de que a formação cultural influencia muitos aspectos da vida das pessoas, interferindo fortemente na saúde ${ }^{7}$.

Com a fala descrita anteriormente, percebe-se que a capacitação destes profissionais exige um ensino-aprendizagem voltado para o aspecto de vida da sua comunidade. Para isso precisam estar em uma constante capacitação para enfrentar os seus desafios e aprender cada vez mais a lidar com as pessoas.

Em consonância, qualquer projeto de capacitação dos profissionais de saúde deve levar em conta um conjunto de premissas, visando também 0 desenvolvimento de uma competência que construa uma instrumentalização técnica e política, centrada na ética ${ }^{14}$.

\section{Educação Continuada para as ACS na ESF}

Todas as ACS recebem educação continuada semanalmente, através de palestras, discussão de casos, reuniões e rodas de discussão. A organização da educação é feita conforme a necessidade de cada microárea. Destacam-se nas falas:

"Sim, é dado a capacitação conforme a situação e a necessidade, ex. busca EFOS (Escola de Formação em Saúde), PMAQ (Programa Nacional de Melhoria do Acesso e da Qualidade da Atenção Básica) e outras empresas contratadas. Uma vez por semana, a equipe da ESF se reúne e vê isso através de palestra e rodas de discussão". (ACS3)

"Sim, dependendo da necessidade de cada área, por ex. vacina, prevenção e agravos de doenças, saneamento básico e muitos outros. Uma manhã por semana a nossa equipe se junta para discutir através de palestras, rodas”. (ACS4) 
"Sim, de acordo com a necessidade do assunto, ele é abordado uma vez por semana, a própria ESF que faz e capacita". (ACS7)

A reunião de equipe desempenha papel importante, pois possibilita que os diversos membros da equipe discutam os problemas que se apresentam na prática cotidiana. A reunião de equipe deve permitir a construção de consensos para resolução dos problemas identificados ${ }^{15}$.

Desta forma salienta-se o quão importante é o entrosamento para troca de saberes entre a equipe interdisciplinar visando um objetivo, que é o de abordar da melhor forma a família.

\section{Organização do processo de trabalho do ACS}

Segundo as ACS, a organização do processo de trabalho é realizada através do cadastro das famílias, visitas domiciliares, preenchimento da ficha A (Sistema de Informação de Atenção Básica - Cadastro da Família), notificação de doenças e troca de informações com a equipe multiprofissional, destacado na fala da ACS3:

"Através de anotações nos cadernos, preenchimento da ficha $A$, e relatamos através de roda de conversa com a equipe técnica, achando as soluções para as dificuldades encontradas". (ACS3)

Ao estar representando a comunidade, este agente acaba abordando o saber profissional da equipe de saúde, com o saber popular da comunidade, assim o trabalho dele acaba se resumindo em três dimensões. Uma técnica, atendendo as famílias através de monitoramento e ações diante das doenças prevalentes e de risco, através das visitas, bem como informações em saúde com base no saber epidemiológico e clínico. Já na dimensão política, ele preocupa-se com a organização da comunidade, auxiliando no fortalecimento da cidadania. E por fim, na assistência social, há uma tentativa de se resolver questões, entre elas a de acesso aos serviços ${ }^{15}$. 
A partir daí, percebe-se então que o trabalho do ACS é bastante extenso, ele passa a ser um representante e porta-voz de toda a comunidade para diferenciados assuntos que abrange até mesmo o município, com questões governamentais.

\section{Papel do enfermeiro no processo de trabalho do ACS}

O esclarecimento de dúvidas, buscando resolução dos problemas encontrados em cada microárea, foi destacado como papel principal do Enfermeiro pelos ACS, destacado na fala:

"Auxilia esclarecendo as dúvidas encontradas em cada micro área, apresentando soluções para as dificuldades que encontramos". (ACS3)

Em consonância ao Agente acima, os outros mencionam:

"Acho que o principal papel é esclarecer o que não entendemos, para que possamos fazer o nosso trabalho da melhor forma". (ACS6)

"O enfermeiro esclarece dúvidas, e eu levo os problemas da comunidade e tentamos juntas resolvê-los". (ACS7)

O papel do enfermeiro dentro da ESF gira em torno de apoiar e supervisionar o trabalho dos agentes comunitários de saúde (ACS), assistir às pessoas que necessitem de cuidados, organizar o trabalho da equipe dentro da Unidade de Saúde (US), planejar ações e executar atividades juntamente à comunidade, buscando a qualidade de vida. Além disso, também atua na assistência às vigilâncias, na saúde da criança, do adolescente, mulher, trabalhador e idoso e desenvolve ações para capacitação dos ACS e técnicos de enfermagem ${ }^{16}$.

Assim, percebe-se a importância do profissional enfermeiro diante de toda a equipe de saúde. Ele possui autonomia, que deve ser trabalhada de forma correta e 
Artigo Original

Atenção à Saúde

ética para suprir a confiança depositada para resolução dos problemas apresentados, sempre levando em conta o bem-estar do paciente e da família.

\section{Facilidades no trabalho do ACS}

O acolhimento das famílias em relação ao trabalho das ACS e o entrosamento com a equipe de saúde da ESF foi destacado como facilidades no processo de trabalho das agentes, observado na fala:

"O bom entrosamento da equipe, assim podes colocar todas as dúvidas encontradas na microárea, o acolhimento que a família nos proporciona também é muito bom". (ACS3)

Destaca-se também a fala de outro agente:

"O acolhimento no momento da visita que a família nos proporciona, e o relacionamento com a equipe da ESF". (ACS4)

Concordando com o colega de trabalho acima, outro ACS destaca que:

"O trabalho para mim é fácil, pois me relaciono bem com as pessoas, e a Unidade também está sempre aberta, disposta a nos ajudar e esclarecer as dúvidas que temos". (ACS7)

Em pesquisa de Peres et al. ${ }^{15}$ as facilidades do trabalho como ACS apontaram também para o trabalho em equipe, referindo-se à construção das relações interpessoais, com possibilidades de discussão de casos/problemas, a liberdade que eles têm para comunicarem-se e dialogar com a equipe da ESF, atitudes de respeito, linguagem comum e acessível, disposição para aprender, corresponsabilização e união. Todas essas facilidades sendo favorecidas pela estratégia de reunião de equipe. 
Artigo Original

Atenção à Saúde

\section{Dificuldades e desafios enfrentados no trabalho como ACS}

Todos os agentes ressaltaram as dificuldades relacionadas para encontrar as pessoas em casa. O mau tempo, a distância entre uma casa e outra, os animais soltos, a precarização das estradas e as casas fechadas, são alguns desses desafios, destacados nas falas:

"Portão fechado e cachorros soltos nos cercados". (ACS1)

"O mau tempo, a distância entre uma casa e outra, por se tratar de uma área rural, e os animais soltos como cão e gado, impedindo que possamos entrar no cercado, pois muitas vezes a família não escuta o nosso chamado e acabamos indo embora e tendo que voltar outra vez". (ACS5)

"O mau tempo, estradas ruins, os cachorros de rua, e muitas pessoas só estão em casa depois do horário de trabalho nosso (depois das cinco horas)". (ACS6)

"A minha maior dificuldade é de encontrar as pessoas em casa, onde muitas vezes tem que ir até umas quatro vezes para achar ela em casa". (ACS7)

Ressalta-se na fala da ACS3, que as dificuldades e desafios estão relacionados à vulnerabilidade social da microárea com casos de tráfico de drogas, a falta de infraestrutura na comunidade e ocorrência de doenças infectocontagiosas. Assim:

"Mau tempo, estradas sem pavimentação, cachorros soltos, tráfico de drogas, doenças contagiosas, como por ex. TB (Tuberculose), falta de saneamento". (ACS3) 
Diante do quadro acima, no que concerne as dificuldades enfrentadas pelo ACS, o estudo de cinco pesquisadores obteve em sua discussão de dados diante dos relatos o surgimento de três categorias: I Dificuldade socioambiental; II Dificuldade de relacionamento; III Dificuldade organizacional ${ }^{17}$.

Percebem-se, diante da leitura deste estudo, que os desafios que estes profissionais possuem são praticamente os mesmos deste, pois os agentes relatam a tarefa bastante complexa abrangendo diversos enigmas rotineiros, os quais vão além da saúde e até mesmo alguns que não dependem deles próprios para serem solucionados.

\section{Conduta das ACS frente às dificuldades e desafios no processo de trabalho}

O ouvir atento os relatos das famílias, esclarecer as dúvidas, dar atenção ao problema de forma discreta e com ética profissional, ouvir muito e falar menos, são condutas das ACS para o enfrentamento das dificuldades e desafios no processo de trabalho na ESF.

"Saber ouvir os problemas dos outros e que às vezes nos colocam muitos". (ACS2)

"Através de visitas domiciliares, ouvir e esclarecer as dúvidas que a família me apresenta, mas mantendo sempre acima de tudo, a ética profissional". (ACS3)

"Ouvir muito e falar menos, e claro esclarecer o que eles não entenderam". (ACS6)

"Dar toda a atenção para o problema e, quando está dentro do meu conhecimento, sempre tento orientar e ser discreta nas visitas. Sempre respeitando os horários convenientes também é muito importante para ser bem-vinda". (ACS7) 
Percebemos diante das falas que o ouvir se torna imprescindível para enfrentar as dificuldades existentes na rotina de trabalho destas profissionais. De um modo geral, a grande maioria delas enfatizou a necessidade de fortalecimento diante do contato pessoal.

Os trabalhadores da área de enfermagem na saúde, dependendo do contexto profissional, acabam por identificar mais facilmente um sofrimento ao invés do prazer. Mas, portanto, se torna indispensável que este trabalhador visualize satisfação e prazer no trabalho, visto que esse fator se relaciona diretamente com a qualidade da assistência prestada ${ }^{18}$.

Neste contexto, o trabalhador, quando está satisfeito e realizado com o seu trabalho, apesar das dificuldades, fará suas atividades mais prazerosamente, desencadeando também a satisfação dos usuários. Assim, vê-se a importância do contentamento e prazer no trabalho na assistência à saúde, sendo que pode influenciar negativamente ou positivamente no cuidado ao paciente e família.

\section{Sugestões das agentes de saúde sobre a temática}

Quanto a este tema, estas profissionais sugeriram maior organização e ética no processo, um profissional psicólogo buscando o cuidado do cuidador, fazer uma maior busca ativa dos casos que estão crescendo nos últimos meses, melhoria do saneamento básico de algumas áreas e também a infraestrutura das estradas, bem como maior controle de animais que vivem soltos.

Por fim, relatam que as próprias acabam sendo um "elo" de confiança entre a comunidade e toda a equipe multiprofissional que trabalha na ESF.

"Mais organização com a equipe e manter mais a ética". (ACS1)

"Talvez pelo menos uma vez ao mês termos um psicólogo para nos manter com a cabeça arejada dos problemas enfrentados por nós". (ACS2) 
"Fazer uma busca ativa ( $T b$, preventivo, mamografia) na microárea. Reivindicações junto aos gestores para melhorar o saneamento básico e infraestrutura das estradas $e$ responsabilizar os danos de animais soltos nas estradas". (ACS3)

"Acredito que desafios existem e sempre irão existir, o importante é nunca perdermos o foco do nosso trabalho que é o elo de confiança que a comunidade deposita em nós e na Unidade". (ACS4)

"Reivindicações para melhorar a pavimentação das estradas, preventivos e vacinas". (ACS5)

"Melhoria nas estradas ajudaria bastante o nosso trabalho. E essa temática é bem importante, pois a maioria das pessoas não conhece o nosso trabalho, o que fazemos e nem para que estamos ali, é importante que a própria comunidade conheça a realidade no ACS, assim dariam mais importância". (ACS6)

"Eu acho super importante, e muito bom discutir sobre isso, pois vejo que tem profissionais ACS que ainda não possuem noção do seu trabalho. Somos o "elo" da nossa comunidade com a Unidade, por isso a importância de saber como o profissional está realizando o seu trabalho e suas prioridades que necessita cada um". (ACS7)

Do mesmo modo, diante dos resultados de um trabalho de 2009, foi ressaltado que o ACS tem um papel bastante relevante, sendo o elo de ligação entre os moradores e a estratégia de saúde, pois além de residir na mesma localidade de atuação, ele conhece as pessoas muito bem, os problemas, as demandas e necessidades principais. Assim, ele acaba entendendo que a saúde da sua 
população depende das condições de vida, do acesso ao trabalho, moradia e alimentação ${ }^{19}$.

Consequentemente, este profissional acaba se envolvendo ainda mais do que deveria com as suas respectivas famílias, sendo que seu trabalho vai além do profissional e paciente, criando assim um respeito mútuo de solidariedade, respeito e confiança.

O trabalho do ACS é uma das formas que aproximam a comunidade da equipe de saúde. Este elo permite troca de compreensão, criando uma ligação muito forte de laços de amizade e carinho entre o paciente e toda equipe multiprofissional, constituindo relações de respeito e consequentemente ajudando na melhora da disposição e da qualidade de vida de toda população que procura a ESF. A família coloca seus medos, aflições, ou frequenta talvez a unidade somente para desabafar ou escutar uma palavra de consolo 20 .

\section{CONCLUSÃO}

Todas as agentes comunitárias de saúde receberam algum tipo de capacitação, onde citaram os mais variados assuntos abordados num período de seis anos. Relataram possuir uma educação continuada, realizada na maioria das vezes semanalmente, através de rodas de discussão, relatos de casos e reuniões.

Segundo as agentes comunitárias, a organização do processo de trabalho é realizada desde o momento em que entram na casa para fazer a visita, fazendo suas anotações e preenchimento de fichas, até o momento em que levam estas informações para a Unidade de Saúde, quando por fim, uma vez por mês, entregam o relatório realizado nas visitas. Assim elas percebem o enfermeiro como a pessoa que esclarece as dúvidas, buscando resolução dos problemas encontrados por cada uma delas em sua determinada região de abrangência.

A facilidade mais evidente foi quanto ao acolhimento das famílias para com o trabalho delas, durante a visita, e também o bom entrosamento com o restante da equipe da ESF, citado pela grande maioria dos entrevistados. Contrastando, dizem que as suas dificuldades estão relacionadas a pessoas não estarem em casa, o mau tempo, a distância entre uma casa e outra na área rural e a falta de apoio das 
Artigo Original

Atenção à Saúde

vigilâncias epidemiológica (animais soltos) e sanitárias (saneamento, estradas em má condição).

O ouvir o que a família tem a declarar com ética e respeito, esclarecendo as dúvidas e dando atenção necessária ao problema de forma discreta, são as principais condutas para o enfrentamento das dificuldades no processo de trabalho destas agentes. Assim elas colocam como sugestão primordial sobre esta temática maior organização e ética no processo, e a melhoria do saneamento básico, bem como infraestrutura de algumas áreas e maior controle dos animais que vivem soltos. Por fim relatam que as próprias se percebem como um elo de confiança entre a comunidade e toda a equipe multiprofissional que trabalha na ESF.

Mesmo grande parte da população não conhecendo o verdadeiro papel do agente comunitário de saúde, este faz parte da equipe, sendo a pessoa que busca informações, e que antes de tudo precisa se identificar em todos os sentidos com a sua comunidade, principalmente na cultura, linguagem e costume, e carece também gostar muito do seu trabalho, aprendendo a repassar informações. Torna-se imprescindível que o agente comunitário entenda que o seu trabalho é fundamental para não somente atualização de dados dentro da Unidade, mas também para o paciente/família que deposita neste profissional confiança e expectativa.

Entende-se assim que trabalhar na área da saúde é atuar para produzir cuidado à saúde de toda a sua população, e que cada trabalhador atua em sua área e tem determinadas responsabilidades, trabalhando para que um único objetivo seja alcançado que é o de promover cuidadosamente o bem-estar da população.

\section{REFERÊNCIAS}

1. Brasil. Portal da Saúde Sistema - Único de Saúde. Brasil: Ministério da Saúde; 2015.

2. Gregori SN. Dificuldades enfrentadas pelos agentes comunitários de saúde (ACS) ao desenvolverem suas atividades em um município do oeste de Santa Catarina. [Monografia]. Chapecó-SC: Unochapeco; 2009.

3. Efos. Estado de Santa Catarina, Superintendência de planejamento e gestão, Diretoria de Educação Permanente em Saúde - Escola de formação em Saúde (EFOS). Apostila para o curso de formação inicial do Agente Comunitário de Saúde. In: II UT, editor.: Secretaria de Estado da Saúde; 2010. p. 174. 
4. Mota RRA, David HMSL. A crescente escolarização do agente comunitário de saúde: uma indução do processo de trabalho? Trab educ saúde. 2010;8:229-48.

5. Brasil. Portaria oㅡ 648 de 28 de março de 2006. Brasil: Ministério Da Saúde; 2006.

6. Ávila MMM. O Programa de Agentes Comunitários de Saúde no Ceará: o caso de Uruburetama. Ciênc saúde coletiva 2011;16:349-60.

7. Marzari CK, Junges JR, Selli L. Agentes comunitários de saúde: perfil e formação. Ciênc saúde coletiva. 2011;16:873-80.

8. Brasil. Agente Comunitário de Saúde. Brasil: Ministério da Saúde; 2015.

9. Júnior JGO. Agentes comunitários de saúde: fatores restritivos e facilitadores do seu trabalho na Estratégia de Saúde da Família [Dissertação]. Rio de Janeiro - RJ: Escola Nacional de Saúde Pública Sergio Arouca; 2012.

10. Teixeira C. Os princípios do Sistema Único de Saúde. Texto de apoio elaborado para subsidiar o debate nas Conferências Municipal e Estadual de Saúde. 2011:10.

11. Sakata KN, Mishima SM. Articulação das ações e interação dos Agentes Comunitários de Saúde na equipe de Saúde da Família. Rev Esc Enferm USP. 2012:665-72.

12. Minayo MCS, Deslandes SF, Neto OC, Gomes R. Pesquisa social: teoria, método e criatividade. 28 ed. Petrópolis, RJ: Vozes; 2010.

13. Brasil. Diretrizes e normas regulamentadoras de pesquisa envolvendo seres humanos. Resolução n. 466/12 Brasil: Conselho Nacional de Saúde. ; 2012.

14. Cotta RMM, Schott M, Azeredo CM, Franceschini SCC, Priore SE, Dias G. Organização do trabalho e perfil dos profissionais do Programa Saúde da Família: um desafio na reestruturação da atenção básica em saúde. Epidemiol serv saúde. 2006;15:7-18.

15. Peres CRFB, Júnior ALC, Silva RF, Marin MJS. O agente comunitário de saúde frente ao processo de trabalho em equipe: facilidades e dificuldades. Rev Esc Enferm USP 2011:905-11.

16. Rodrigues LCR, Juliani CMCM. Processo de cogestão na estratégia saúde da família: perspectiva de enfermeiros. Ciênc cuid saúde. 2010;9(2):390-7.

17. Silva BT, Arruda LB, Dantas TM. Dificuldades Enfrentadas pelo Agente Comunitário de Saúde: Compreensão Necessária para Prática de Enfermagem. 2012:12.

18. Lopes DMQ. Prazer, sofrimento e estratégias defensivas dos agentes comunitários de saúde no trabalho [Dissertação]. Santa Maria: Universidade Federal de Santa Maria; 2010. 
Artigo Original

Atenção à Saúde

19. Silva PR, Ribeiro GTF. ACS: Elo de ligação entre comunidade carente e a ESF. Vita et Sanitas. Trindade-GO2009. p. 66-85.

20. Brasil. O trabalho do agente comunitário de saúde. Brasília: Ministério da Saúde. Secretaria de Atenção à Saúde. Departamento de Atenção Básica. ; 2009. p. 84. 